\title{
IoT based Smart System for Human Safety
}

\author{
Akash Wadhawane \\ JSPM's Imperial College Of Engineering and Research, Pune \\ BE Computer \\ Priyanka Ghodke \\ JSPM's Imperial College Of Engineering and Research, Pune \\ BE Computer
}

\author{
Amir Attar \\ JSPM's Imperial College Of Engineering and Research, Pune \\ BE Computer \\ Prasad Petkar \\ JSPM's Imperial College Of Engineering and Research, Pune \\ BE Computer
}

\author{
Shital Thokal \\ Professor JSPM's Imperial College Of Engineering and Research, Pune \\ Computer Department
}

\begin{abstract}
Now a days in the world, the basic question comes in every persons mind, day by day increase in harassment is affecting their safety and security. Not for only Women, There are many Old Age Peoples and Physically Weak Peoples. In this paper we came with a new perspective to use technology for Human safety. We have come up with an idea which will change the mindset of every person about Human safety. A day when media broadcasts more of womens achievements rather than harassment, its a feat achieved! Since we (humans) cant respond aptly in critical situations, the need for a device which automatically senses and rescues the victim is the venture of our idea in this paper. We are going to built a smart device, which is having combination of multiple components, basically a wearable Smart Device which continuously communicates through the internet with a Smart phone. The application is programmed and all the health related data of the user. This generates a signal which is transmitted to the smart phone. The software or application has access to GPS and Messaging services which is preprogrammed in such a way that whenever it receives emergency signal, it can send help request along with the location co-ordinates to the nearest Police station, relatives and the people in the near radius who have application. This action enables help instantaneously from the Police as well as Public in the near radius who can reach the victim with great accuracy.
\end{abstract}

\section{Keywords}

Smart Device;GPS Technology;Sensors;Body Sensor Network(BSN);SMS gateway

\section{INTRODUCTION}

Now a days in most of the countries innocent women are brutally harassed by some of the people. Women are facing such a problem very oftenly. The day by day increase in such situation women are afraid of leaving the house at night. So basically women are bounded to such situation in some of countries women doesn't feel safe at night.Harassment is not only the issue. In most of countries children are threaten and get kidnapped. Now a days this is one of the major issue. One of the major factor for doing this project is some of people has health related issues. Sometime they did not get proper medication on time. In some situation it might leads towards the death that person if did not get any kind of help from any one.These three are the major aspect for doing this project. These three aspect motivated us to do this project which will help humans in a better way.

\section{EXISTING SYSTEM}

\subsection{SHE (Society Harnessing Equipment)}

It is a garment embedded with an electronic device. This garment has an electric circuit that can generate $3800 \mathrm{kV}$ which can help the victim to escape. In case of multiple attacks it can send around 80 electric shocks.

\subsection{ILA Security}

The co-founders of this system, have designed three personal alarms that can shock and disorient potential attackers and hence safegaurd the victim from perilous situations.

\subsection{AESHS (Advanced Electronics System for Human Safety)}

It is a device that helps track the location of the victim when attacked using GPS facility.

\subsection{VithU app}

This is an emergency app initiated by a popular Indian crime television series Gumrah aired on Channel [V]. When the power button of the Smartphone is pressed twice consecutively, it begins sending alert messages with a link of the location of the user every two minutes to the contacts.

\subsection{Smart Belt}

This system is designed with a portable device which resembles a normal belt. It consists of Arduino Board, screaming alarm and 
pressure sensors. When the threshold of the pressure sensor crosses, the device will be activated automatically. The screaming alarm unit will beactivated and send sirens asking help.

\subsection{HearMe}

In this system, if any emergency occurs then it will notify the victims and the their family members at the same time.[4]

\section{PROPOSED SYSTEM}

In proposed system we are going to build a smart wearable device in the form of wearable band. The band is integrated with some sort of sensors which will not only help in harassment related issues but will also help in medical issues. The device will generate a message with GPS co-ordinates and will be send to nearest police station, nearest active peoples, relatives or nearest ambulance as per the situation.The message will be send through the internet or SMS gateway,as per the condition. It can also be used as a health monitoring system by using BSN.

\section{SMART DEVICE}

The smart device is integrated with micro controller which is small in size and cheap in price.The micro controller supports minimum three sensors,those sensors are pulse rate sensor, temperature sensor and Bluetooth sensor to form BSN.The smart band then communicates with the smart phone through mobile application. The smart device having trigger button on it,which is used to send the message to the smart phone application through Bluetooth.

\section{GPS TECHNOLOGY}

The global positioning system(GPS) is used to track the real time location of the device.The GPS is able to determine the latitude and longitude of the device, with the help of various satellites. The location of the device is transmitted every second.

\section{SENSORS}

A device which detects or measures a physical property and records, indicates, or otherwise responds to it. Sensors are the device which are used to get information of the things which a human cant do it manually. Sensors can sensed the environment and produce the output according to that. The specific input could be light, heat, motion, moisture, pressure, or any one of a great number of other environmental phenomena.

We are using three sensors are PR sensor, Temperature sensor and Bluetooth sensor. Pulse rate sensor is used to calculate human pulse rate.Temperature sensor is used to calculate the temperature of human body.Bluetooth sensor is used to transfer the data from smart device to smart phone.

Sensors are easily available in market and some of them are costly as per there requirements. As sensors help use to get information of anything from anywhere.

\section{BODY SENSOR NETWORK}

A BSN(Body Sensor Network) is a special purpose network designed to operate autonomously to connect to various medical sensors and implant located inside or outside of the human body.

\section{SMS GATEWAY}

An SMS gateway allows a computer to send or receive Short Message Service (SMS) transmissions to or from a telecommunications network. Most messages are eventually routed into the mobile phone networks. The connection to the mobile network is made by acquiring a SIM card number from the mobile operator and installing it in the gateway. Typically, direct-to-mobile gateway appliances are used for hundreds to thousands of text messages per month. More modern appliances now offer the capability of send up to 100,000 messages each day. we are using SMS gateway to send message to customers after receiving their allocated ration. We have found that is proposed system is more efficient then the existing system .

\section{ACKNOWLEDGEMENT}

We would like to take this opportunity to thanks Prof. S. S. Thokal for giving us all the help and guidance we needed. We are really grateful for her kind support. Her valuable suggestions were very helpful. We are also grateful towards Dr. S. R. Todmal, for his indispensable support and suggestions for time to time.

\section{REFERENCES}

(1) "Design of a women safety device ",Divya Chitkara; Nipun Sachdeva; Yash Dev Vashisht ,2016 IEEE Region 10 Humanitarian Technology Conference (R10-HTC)

(2) "Prototype of an intelligent system based on RFID and GPS technologies for women safety ",Shaik Mazhar Hussain; Shaikh Azeemuddin Nizamuddin; Rolito Asuncion; Chandrashekar Ramaiah; Ajay Vikram Singh ,2016 5th International Conference on Reliability, Infocom Technologies and Optimization (Trends and Future Directions) (ICRITO)

(3) "Design and development of an IOT based wearable device for the safety and security of women and girl children ",Anand Jatti; Madhvi Kannan; R M Alisha; P. Vijayalakshmi; Shrestha Sinha ,2016 IEEE International Conference on Recent Trends in Electronics, Information \& Communication Technology (RTEICT)

(4) "HearMe: A Smart Mobile Application for Mitigating Women Harassment", Saad Ahmed Akash, Md. Abdur Razzaque, Md. Al-Zihad, Tamal Adhikary, Arifa Sharmin, 2016 IEEE International WIE Conference on Electrical And Computer Engineering.

(5) "Design and implementation of a rescue system for safety of women ",Madhura Mahajan; KTV Reddy; Manita Rajput, 2016 International Conference on Wireless Communications, Signal Processing and Networking (WiSPNET)

(6) "A Secure IoT-Based Healthcare System With Body Sensor Networks", Kuo-Hui Yeh ,IEEE Access

(7) "Smart foot device for women safety", Nandita Viswanath; Naga Vaishnavi Pakyala; G. Muneeswari, 2016 IEEE Region 10 Symposium (TENSYMP)

(8) "Design and implementation of safety armband for women and children using ARM7", Glenson Toney; Fathima Jabeen; Puneeth S, 2015 International Conference on Power and Advanced Control Engineering (ICPACE)

(9) "Safetipin An innovative mobile app to colect data on womens safety in indian cities.",Kalpana Viswanath and Ashish Basu.,Gender and Development 2015. 
(10) "Movefree: A ubiquitous system to provide wo men safety. W CI ",Sohini Roy, Abhijit Sharma, and Uma Bhattacharya.,2015 Proceedings of the T hird International Symposium on Women in Computing and Informatics, ACM, New York, USA

(11) "Mobile Wearable Communications ", H. Moustafa, h. Kenn, K. Saryafain, W. Scanlon and Y. Zhang, 2015 IEEE wireless Communication. communication

(12) "The Internet Of Things For Health Care: A Comprehensive Survey", S. M. Riazul Islam, Daehan Kwak, Md. Humaun Kabir, mahmud Hossain, And Kyung-sup Kwak, IEEE Access, 2015.

(13) "An IoT- Aware Architecture for Smart Healthcare System", uca Catarinucci, Danilo de Donno, Luca Mainetti, Luca Palano, Luigi Patrono, Maria Laura Stefanizzi, and Luciano Tarricone,IEEE JOURNAL,2015.

(14) "Smart girls security system", B.Chougula, 2014 International Journal of Application or Innovation in Engineering \& Management.

(15) "Smart security solutions ", Vamil B. Sangoi, 2014 International Journal of Current Engineering and Technology.

(16) "GPS Based Advanced Soldier Tracking With Emergency Messages \& Communication System ",Palve Pramod, 2014 International Journal of Advance Research in Computer Science and Management Studies Research Article.

(17) "Design and Implementation of Real Time Embedded TeleHealth Monitoring System",Suhas Kale and C. S. Khandelwal, 2013 International Conference on Circuits, Power and Computing Technologies. 